\title{
Response and Motion Performance of Offshore 5MW National Renewable Energy Laboratory Wind Turbine Platform Based on Nicobar Costal Ocean State
}

\author{
M. R. NithinRaj*, K. M. Sankaranarayanan
}

Civil Engineering Department SIMAT Kerala Technological University, Kerala, India

\section{$P A P E R$ INFO}

Paper history:

Received 16 May 2019

Accepted in revised form 23 August 2019

\section{Keywords:}

Ansys AQWA

Hydrostatic Analysis

Mini Tension Leg Platform Wind Turbines

National Renewable Energy Laboratory

Tension Leg Platform

\section{$A \quad B \quad S \quad T \quad R \quad A \quad C \quad T$}

Wind turbines on floating support platforms are designed to be installed in a deep offshore environment several miles off the coast and in water depths greater than $60 \mathrm{~m}$. Effects from sea ice, varying mean sea level, and marine growth constitute additional loads that must be considered in a real design process. Design Modeler is the ANSYS tool used to create geometry for hydrodynamic systems. Surface bodies are only supported by ANSYS AQWA thus entire solid body which is created using the design modeler is transformed in to surface body. Four different mini Tension leg platforms were prepared all the dimensions and standards are followed from the guidelines of national renewable energy laboratory United States. This paper focused on the motion performance of tension leg platform supported wind turbine prototypes in Nicobar coast of India. The wind, wave and ocean current data were obtained and inputted in to the AQWA modules and the result is validated with respect to time domain.

doi: $10.5829 /$ ijee.2019.10.03.10

\section{INTRODUCTION}

The design for a floating offshore wind turbine tension leg platform (FOWT-TLP) is economical, technically feasible and experiences less motion compared to other floating structures, especially in deep water. In the past decades, the offshore wind industry has developed from applications in shallow water to ever deeper, more remote locations with harsh environments. In these progressively large water depths, bottom founded support structures become no longer applicable and floating support Structures could provide a viable alternative. Various studies have focused on floater designs for this application and multiple prototypes have been developed. A requirement for deep-water floating offshore wind turbines is the development of reliable, viable floating-platform support structures. To develop cost-effective, high-performance floating wind turbines with structural and dynamic integrity and reliability onshore and shallow-water fixed-bottom offshore turbine loads mainly are dominated by aerodynamics $[1,2]$. For offshore floating turbines, hydrodynamic loads become more important. The dynamic response of a floating wind turbine depends on several elements, such as the aerodynamic loads on the rotor, the hydrodynamic loads on the floater, the restoring effect of the mooring lines and the structural properties of the turbine and floater $[3,4]$.

Offshore wind turbines are subjected to combined wind and wave loadings. Severe environmental condition is probable to happen in marine areas when the wind speed and the wave height is high. Offshore wind turbines require to be stable and not to fail dynamically in severe environmental conditions. Environmental pollution and global warming has increased demand for renewable energy. In this regard, different studies and majors have focused on renewable energies. Among different sources of renewable energy, wind energy is the most reliable and practical type of renewable energy which can be generated using wind turbines $[4,5]$.

\section{MODEL DESCRIPTION AND INPUT}

The demand of electrical energy is getting higher around the world every other passing day and India is no such exception. With limited non-renewable resources of energy to generate electricity, India is slowly shifting its focus towards renewable resources of energy like solar and wind to produce electricity. Here in this project we majority focuses on the design and response of the floater platforms which carry $5 \mathrm{MW}$ wind turbines as floating 
entity. which carry $5 \mathrm{MW}$ wind turbines as floating entity. A major breakthrough in the offshore wind turbine research is the introduction of mini TLP's which are very much small and cost effective than normal TLP's for wind extraction purposes. ANSYS AQWA a commercial suite of hydrodynamic program, which is widely used in the offshore industry is adopted in this project to execute the hydrostatic and hydrodynamic analysis.

Nicobar locality with latitudinal and longitudinal extent is selected according to similar ocean floor depth without much undulation in bathymetric data. Such offshore floating innovations are totally unknown for Indian community and no such projects are proposed or commissioned till now in India even Indian costal wind have much intensity. Here comes the relevance of the work. The parameters like wind, wave, ocean current etc. will vary according to variation in localities and their variations are considered from INCOIS portal and inputted in to AQWA. Such modern innovations will definitely become an add up to the energy demands of a developing entity India. The Horizontal and projected view of the wind turbine floater TLP modeled is shown in Figure 1. Four modeled National Renewable Energy Laboratory (NREL) tension leg platforms are shown in Figure 2.
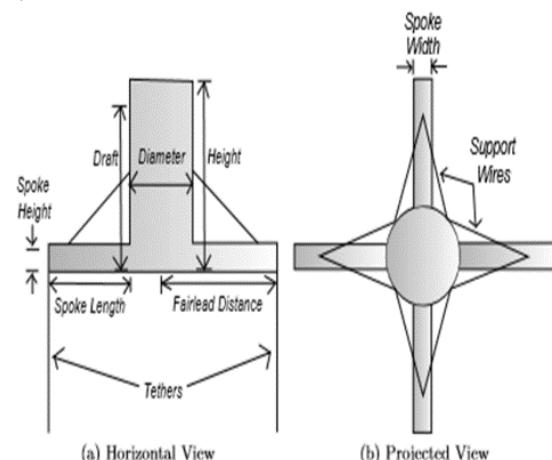

Figure 1. Horizontal and projected view of the wind turbine floater TLP modeled

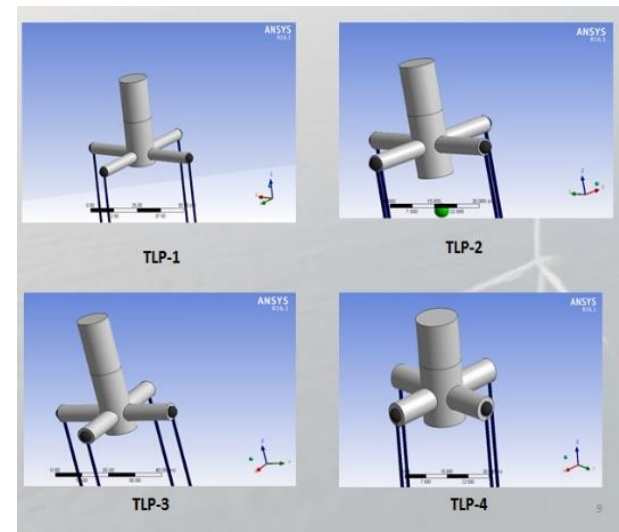

Figure 2. Four modeled National Renewable Energy Laboratory (NREL) tension leg platforms
In this paper, a thermodynamic model of ethanolgasoline fueled SI engine is provided to predict engine performance and emissions. The model is sufficient for all range of fuel composition from pure gasoline to pure ethanol. Provided model is calibrated and obtained data are validated via experiments; then, the model is used to investigate the effects of engine inlet parameters such as engine speed, equivalence ratio and the proportion of ethanol in fuel, on performance and emissions. The design point of each study is introduced due to engine's best performance.

All data about wind, wave, ocean current etc. are collected from the portal online the corresponding directions of the parameters are also inputted in to ANSYS AQWA. The properties of modeled tension leg platforms are summarized in Table 1. The ocean state data of locality are shown in Table 2.

TABLE 1. Properties of modeled tension leg platforms

\begin{tabular}{|c|c|c|c|c|}
\hline Parameters & TLP-1 & TLP-2 & TLP-3 & TLP-4 \\
\hline $\begin{array}{l}\text { Draft } \\
\text { Diameter }\end{array}$ & $15 \mathrm{~m}$ & $12 \mathrm{~m}$ & $12 \mathrm{~m}$ & $15 \mathrm{~m}$ \\
\hline $\begin{array}{l}\text { Draft } \\
\text { Length }\end{array}$ & $40 \mathrm{~m}$ & $35 \mathrm{~m}$ & $45 \mathrm{~m}$ & $30 \mathrm{~m}$ \\
\hline $\begin{array}{l}\text { Spoke } \\
\text { Diameter }\end{array}$ & $5.5 \mathrm{~m}$ & $6 \mathrm{~m}$ & $7 \mathrm{~m}$ & $8 \mathrm{~m}$ \\
\hline $\begin{array}{l}\text { Spoke } \\
\text { Length }\end{array}$ & $25 \mathrm{~m}$ & $20 \mathrm{~m}$ & $18 \mathrm{~m}$ & $15 \mathrm{~m}$ \\
\hline $\begin{array}{l}\text { Gravity } \\
\text { Point }\end{array}$ & $\begin{array}{c}(0,0 \\
-32.988)\end{array}$ & $\begin{array}{c}(0,0, \\
-35.426)\end{array}$ & $\begin{array}{c}(0,0, \\
-41.681)\end{array}$ & $\begin{array}{c}(0,0, \\
-36.857)\end{array}$ \\
\hline $\begin{array}{l}\text { Total Mass } \\
T\end{array}$ & $\begin{array}{c}1468632 \\
\mathrm{~kg}\end{array}$ & $\begin{array}{c}1868740 \\
\mathrm{~kg}\end{array}$ & $\begin{array}{c}1644921 \\
\mathrm{~kg}\end{array}$ & $\begin{array}{c}2648716 \\
\mathrm{~kg}\end{array}$ \\
\hline $\begin{array}{l}\text { Number of } \\
\text { Spokes }\end{array}$ & 4 & 4 & 4 & 4 \\
\hline
\end{tabular}

TABLE 2. Ocean state data of locality

\begin{tabular}{lc}
\hline \multicolumn{1}{c}{ Ocean state properties } & Value \\
\hline Latitude & $6.5^{\circ} \mathrm{N}$ to $7^{\circ} \mathrm{N}$ \\
Longitude & $92.5^{\circ} \mathrm{E}$ to $93^{\circ} \mathrm{E}$ \\
Depth (bathymetric data) & 3286 \\
Wave height & $2.5 \mathrm{~m}$ \\
Wave direction & $20^{\circ} \mathrm{N} \mathrm{E} \mathrm{\&} 20^{\circ} \mathrm{S} \mathrm{W}$ \\
Short wave period & $8 \mathrm{~s}$ \\
Long wave period & $9 \mathrm{~s}$ \\
Wind speed & $4 \mathrm{~m} / \mathrm{s}$ \\
Wind direction & $45^{\circ} \mathrm{N} \mathrm{W}$ \\
Current velocity & $0.6 \mathrm{~m} / \mathrm{s}$ \\
Current direction & $20^{\circ} \mathrm{N} \mathrm{W}$ \\
\hline
\end{tabular}


Locality selected based on latitude and longitude is shown in Figure 3. Wave data collected for Andaman is shown in Figure 4. The wave period data collected for Andaman is illustrated in Figure 5; while the wind data collected for Andaman are shown in Figure 6.

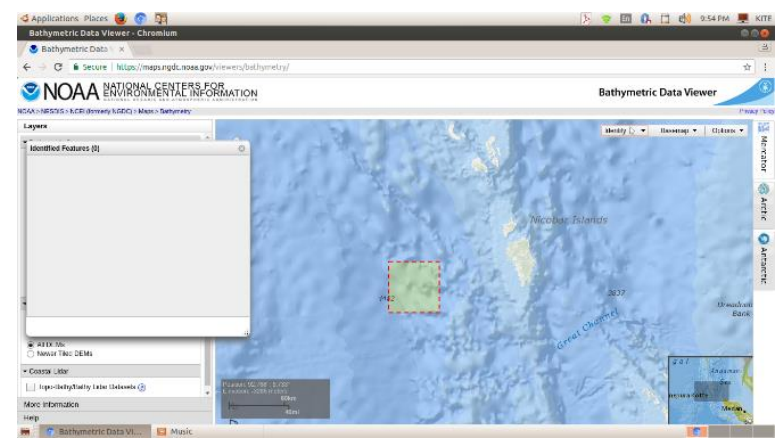

Figure 3. Locality selected based on latitude and longitude

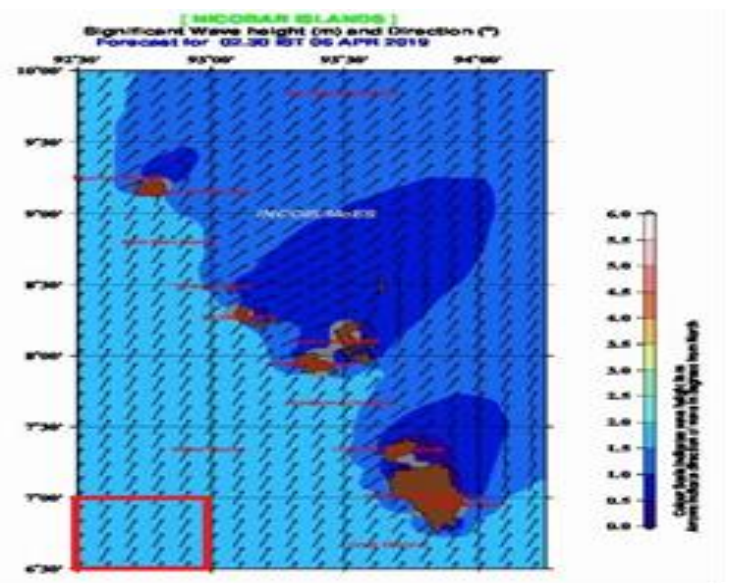

Figure 4. Wave data collected for Andaman

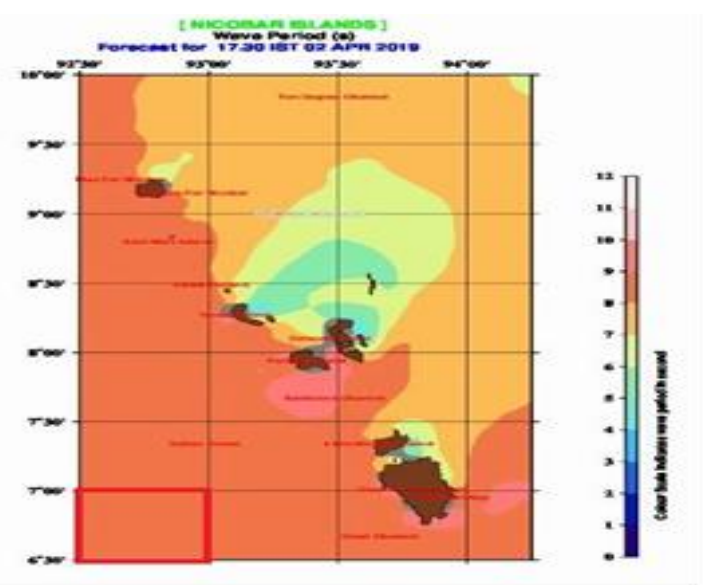

Figure 5. Wave period data collected for Andaman

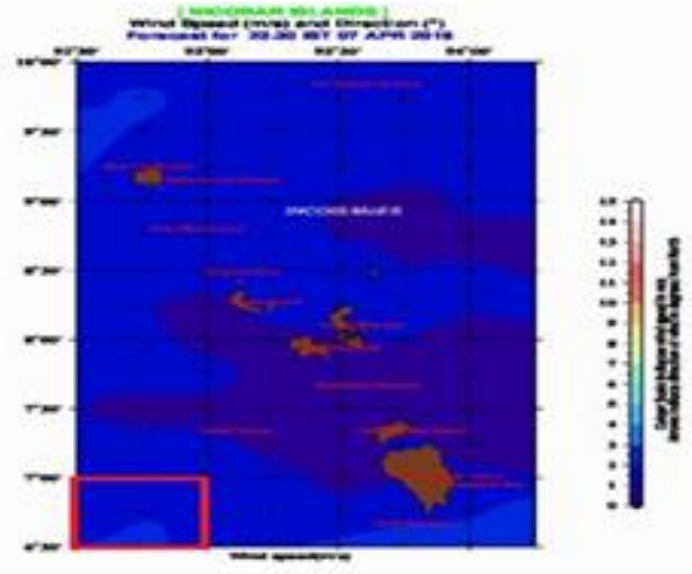

Figure 6. Wind data collected for Andaman

\section{RESULTS AND DISCUSSION}

Hydrostatic results obtained from ANSYS AQWA are provided below. Motion performance of four NREL TLP Supported wind turbines are done hydrostatic analysis and hydrodynamic response studies are done.

Figure 7 illustrate the ocean current data collected for Andaman. The hydrostatic results of TLP-1 Andaman locality is shown in Figure 8. The hydrostatic result TLP2 Andaman locality is demonstrated in Figure 9. In addition, Figure 10 shows the hydrostatic result TLP-3 Andaman locality. Figure 11 demonstrate the hydrostatic result TLP-4 Andaman locality.

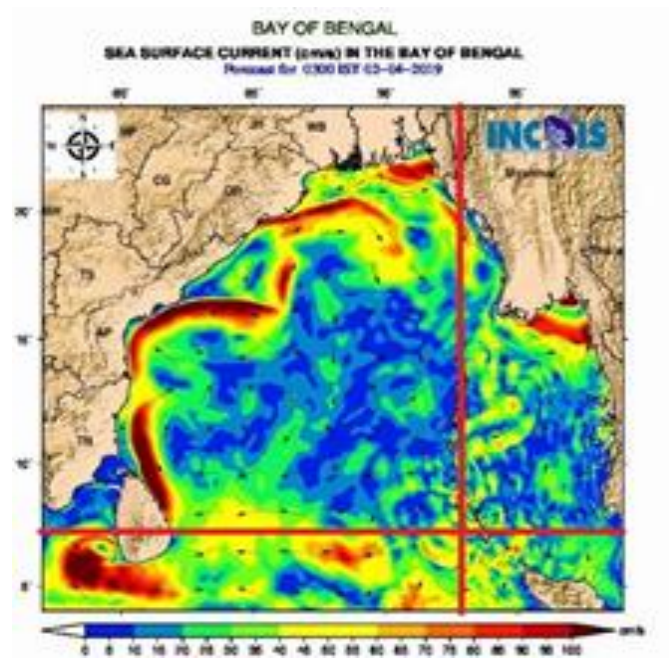

Figure 7. Ocean current data collected for Andaman 


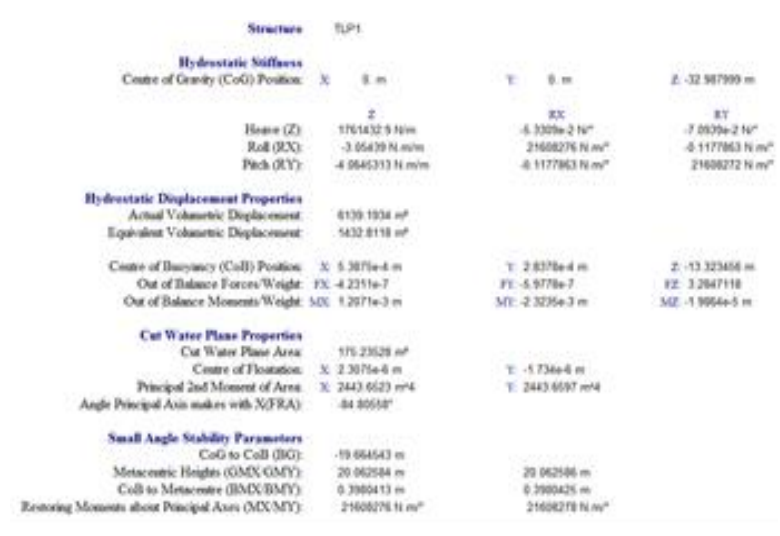

Figure 8. Hydrostatic result TLP-1 Andaman locality

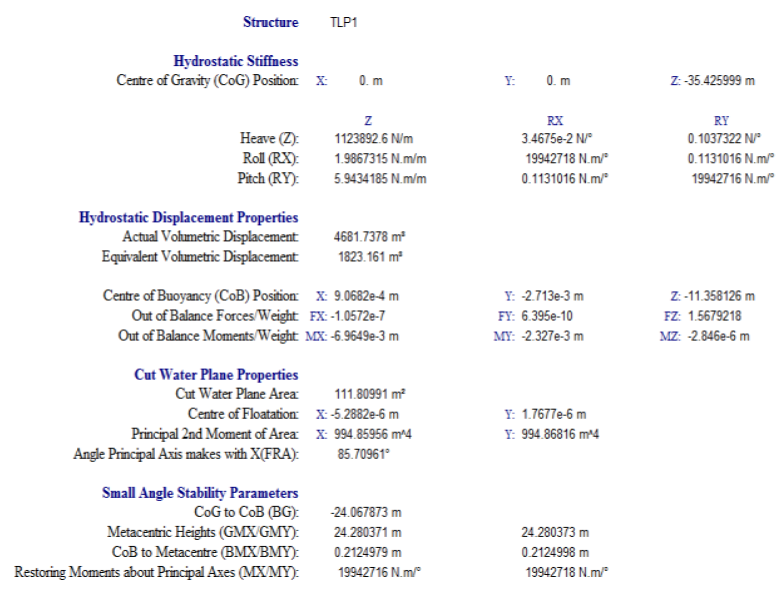

Figure 9. Hydrostatic result TLP-2 Andaman locality

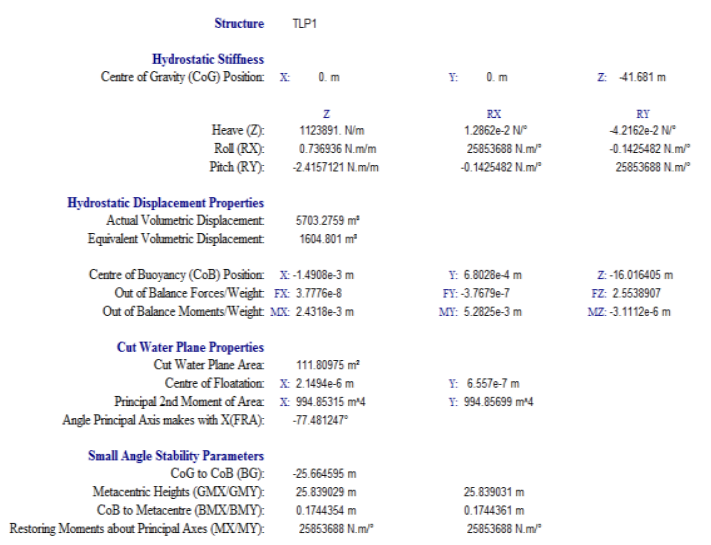

Figure 10. Hydrostatic result TLP-3 Andaman locality

Panel pressure of four NREL TLP's located at Andaman locality is shown in Figure 12. The hydrodynamic motion characteristics are summarized in Table 3.

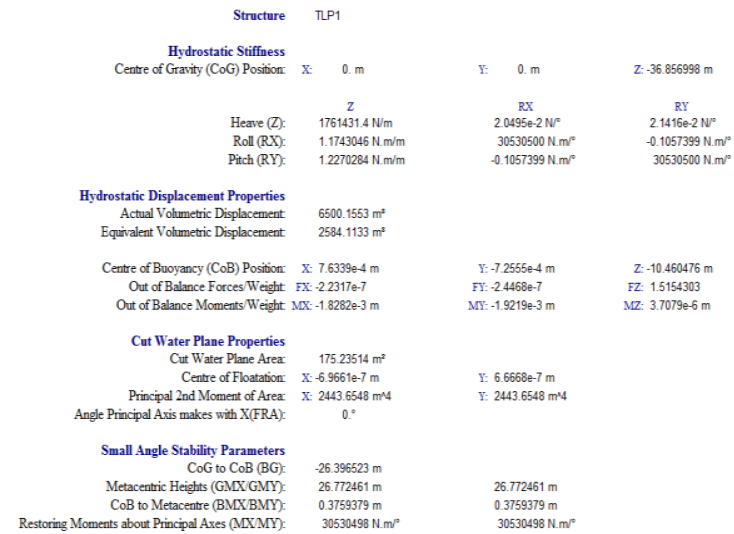

Figure 11. Hydrostatic result TLP-4 Andaman locality

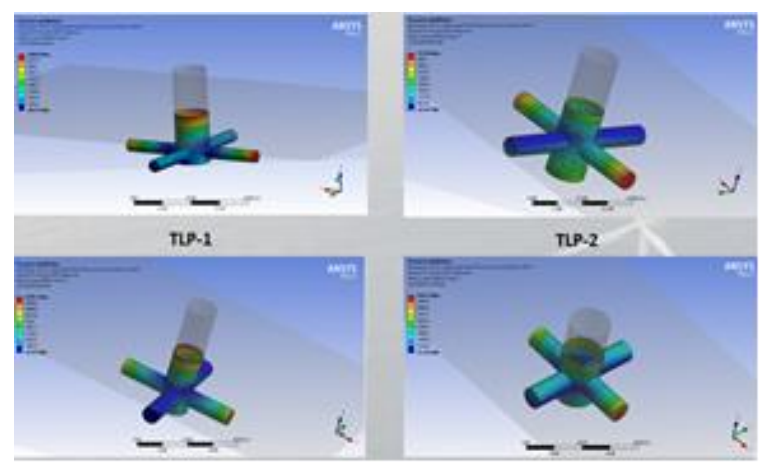

Figure 12. Panel pressure of four NREL TLP's located at Andaman locality

TABLE 3. Hydrodynamic motion characteristics

\begin{tabular}{lcccc}
\hline Location & Surge(M) & Sway (M) & Heave (M) & Remarks \\
\hline Nicobar Tlp-1 & 0.000075 & 0.00015 & -19.5577 & $\begin{array}{c}\text { Tlp With Best } \\
\text { Surge Perfomance }\end{array}$ \\
Nicobar Tlp-2 & 0.0008 & -0.0023 & -25.47 & \\
Nicobar Tlp-3 & -0.001375 & 0.0006 & -27.406 & $\begin{array}{c}\text { Surge Deviate } \\
\text { Slightly }\end{array}$ \\
Nicobar Tlp-4 & 0.0008 & -0.0005 & -25.6 & \\
\hline
\end{tabular}

\section{CONCLUSION}

All the tension leg platforms except the third one will give satisfactory regular response but the third tension leg platform fails due to deviation in the surge. The surge motion response with respect to time gives a deviating output hence the structure will not be stable in the given condition. The wind industry has developed very fast in recent years, moving from onshore to offshore in shallow water and then in deep water. Many floating wind turbine concepts have been proposed for water depth larger than 
100-200 m. Tension leg platform wind turbines (TLPWTs) are among the concepts that are under consideration for deeper water. There is an increasing interest in using offshore wind turbines in deeper waters. The tension leg platform wind turbine (TLPWT) has seen as a promising concept for this purpose. The TLP-1 resulted in the best surge performance among four prototypes.

\section{REFERENCES}

1. Jonkman, J.M., 2007, Dynamics modeling and loads analysis of an offshore floating wind turbine (No. NREL/TP-500-41958), National Renewable Energy Lab. (NREL), Golden, CO (United States).
2. Matha, D., 2010, Model development and loads analysis of an offshore wind turbine on a tension leg platform with a comparison to other floating turbine concepts: April 2009 (No. NREL/SR500-45891), National Renewable Energy Lab. (NREL), Golden, CO (United States).

3. Abid, M., K. S. Karimov, H. A. Wajid, F. Farooq, H. Ahmed, and O. H. Khan, 2015, Design, development and testing of a combined Savonius and Darrieus vertical axis wind turbine." Iranica Journal of Energy and Environment 6(1) pp. 1-4.

4. Wang, C.M., Utsunomiya, T., Wee, S.C. and Choo, Y.S., 2010, Research on floating wind turbines: a literature survey, The IES Journal Part A: Civil \& Structural Engineering, 3(4), pp.267-277.

5. Belgacem, K., Mezouar, A. and Massoum, A., 2013. Sliding mode control of a doubly-fed induction generator for wind energy conversion. International Journal of Energy Engineering, 3(1), pp.30-36. 